\title{
3DVAR assimilation of SSM/I data over the sea for the IOP2b MAP case
}

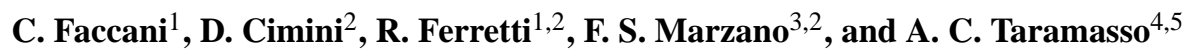 \\ ${ }^{1}$ Department of Physics, University of L'Aquila, Italy \\ ${ }^{2}$ CETEMPS, University of L'Aquila, Italy \\ ${ }^{3}$ Department of Electrical Engineering, University of L'Aquila, Italy \\ ${ }^{4}$ CIMA, Inter-university Center for Environmental Monitoring, Savona, Italy \\ ${ }^{5}$ DIST, University of Genova, Italy
}

Received: 24 October 2004 - Revised: 19 April 2005 - Accepted: 20 April 2005 - Published: 4 July 2005

\begin{abstract}
Data assimilation by 3DVAR of data from the Special Sensor Microwave/Imager (SSM/I) has been performed to study the IOP2b case (19-21 September 1999) of the Mesoscale Alpine Programme (MAP). Only data over the sea surface are used to avoid the contamination of the surface emissivity. Moreover, the rainy data are filtered out because the assimilation algorithm of 3DVAR does not take into account the scattering processes. SSM/I data are assimilated in two different ways: as Brightness Temperature directly, or as Precipitable Water and surface wind speed retrieved from the Brightness Temperature. The effect of the thinning of the observations has been studied and a set of sensitivity test cases has been carried out; the one by one removal of the $\mathrm{SSM} / \mathrm{I}$ frequencies from the initial dataset allows to evaluate their impact on the Initial Conditions. A few experiments are performed using these new Initial Conditions to initialize the MM5 (PSU/NCAR) model. The results show that the assimilation of the retrieved quantities, i.e. Precipitable Water and surface wind speed, does not produces large improvement in the Initial Conditions. Vice versa, the assimilation of the Brightness temperatures produces a large variability of the Initial Conditions. The forecast experiments show that the model is very sensitive to the $22 \mathrm{GHz}$ and $37 \mathrm{GHz}$ frequencies.
\end{abstract}

\section{Introduction}

Assimilation of satellite data over the sea is an easy way to get a lot of information on the earth surface where observations are scarce. Moreover, whereas the standard observations have a random distribution and a low spatial density over the land surface, the satellite data completely scan wide areas beneath their orbit track. It provides a large amount of data that can be used to improve the initialization of the math-

Correspondence to: C. Faccani

(claudia.faccani@aquila.infn.it) ematical models for the weather forecast. The Special Sensor Microwave/Imager (SSM/I) (Hollinger et al., 1990) radiometer can provide, by retrieval from the Brightness Temperature recorded, information on the atmospheric moist variables, such as Precipitable Water (PW), Cloud Liquid Water (CLW) and Rain Rate (RR). These variables quickly change in space and time and they strongly influence the weather forecast. Therefore, in the last few years, many efforts have attemped to use these data for an accurate model initialization. The assimilation of the SSM/I data is mostly performed using retrieved quantities (Tsuyuki, 1997; Hou et al., 2004; Gerard and Saunders, 1999) and not the Brightness Temperature directly. This is because the Radiative Transfer Equation (RTE) requires a good modelling of the atmosphere, but if rain is present, the scattering processes are too complex to be correctly reproduced. In this study, a simplified algorithm without scattering processes is used, therefore rainy data will be filtered out. A comparison between the assimilation of the retrieved quantities and the Brightness Temperature is performed.

\section{$2 \mathrm{SSM} / \mathrm{I}$ data}

The SSM/I passive microwave radiometer operates on the DMSP satellites. It has four frequencies at 19.35, 22.235, 37.0 , and $85.5 \mathrm{GHz}$ with dual polarization except the $22 \mathrm{GHz}$ frequency, which works on vertical polarization only. It has a conical scan and a swath of $1400 \mathrm{~km}$. On each scan it takes 128 uniformly spaced samples at the $85 \mathrm{GHz}$ frequency with a spatial resolution of $12.5 \mathrm{~km}$. The others frequencies are sampled with a double temporal and spatial resolution, i.e. $8.4 \mathrm{~ms}$ and $25 \mathrm{~km}$. This spatial resolution is of the same order of the model grid step in the 1st domain (outmost box in Fig. 1), i.e. $27 \mathrm{~km}$. Note also that the area under consideration, which corresponds roughly to $3 \times 10^{6} \mathrm{~km}^{2}$, is scanned within few minutes during the satellite overpass. For more details, see Hollinger et al. (1990). 


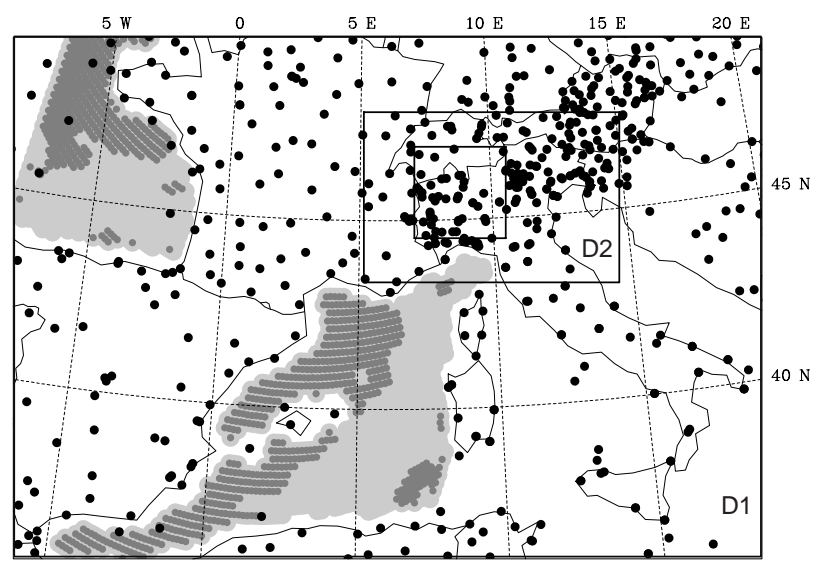

Fig. 1. Model domains. The light gray dots are the SSM/I pixels selected by 3DVAR for Brightness Temperature or water vapor data assimilation; the dark gray dots are the points where the surface wind speed is available; the black points are the land and sea surface stations used to validate the data assimilation results on the Initial Conditions.

In Fig. 1 the light gray dots reproduce the SSM/I swath over sea at 0600UTC 20 September 1999. SSM/I data are assimilated into the model in two different ways: as Brightness Temperatures or as retrieved quantities, as surface wind speed (Goodberlet et al., 1989) and Precipitable Water (Gerard and Eymard, 1998).

\section{3DVAR}

The 3-Dimensional Variational Data Assimilation (Courtier et al., 1998; Gustafsson et al., 2001; Barker et al., 2004) has been used to improve the Initial Conditions by SSM/I data. 3DVAR assimilates the data by minimizing the cost function $J$ defined as

$$
\begin{aligned}
J= & \frac{1}{2}\left(x^{b}-x\right)^{T} \mathbf{B}^{-1}\left(x^{b}-x\right)+ \\
& \frac{1}{2}\left(y^{o}-H\left(x^{b}\right)\right)^{T} \mathbf{R}^{-1}\left(y^{o}-H\left(x^{b}\right)\right)
\end{aligned}
$$

where $x^{b}$ is the generic variable of the first guess, $y^{o}$ is the observation, and $H$ is the operator that converts the model state variables to the observed variables at the observation location. $\mathbf{B}$ and $\mathbf{R}$ are the error covariance matrices for the first guess and for the observations, respectively. The solution of the minimization produces improved Initial Conditions, which are the best compromise between the first guess and the observations.

In this case, the ECMWF (European Center for MediumRange Weather Forecast) analysis has been used as first guess.

The package of subroutines used by 3DVAR to assimilate the SSM/I Brightness Temperatures is based on the Petty algorithms (Petty and Katsaros, 1992, 1994; Petty, 1994a,b, 1997). The RTE model solves the problem for a non scat-

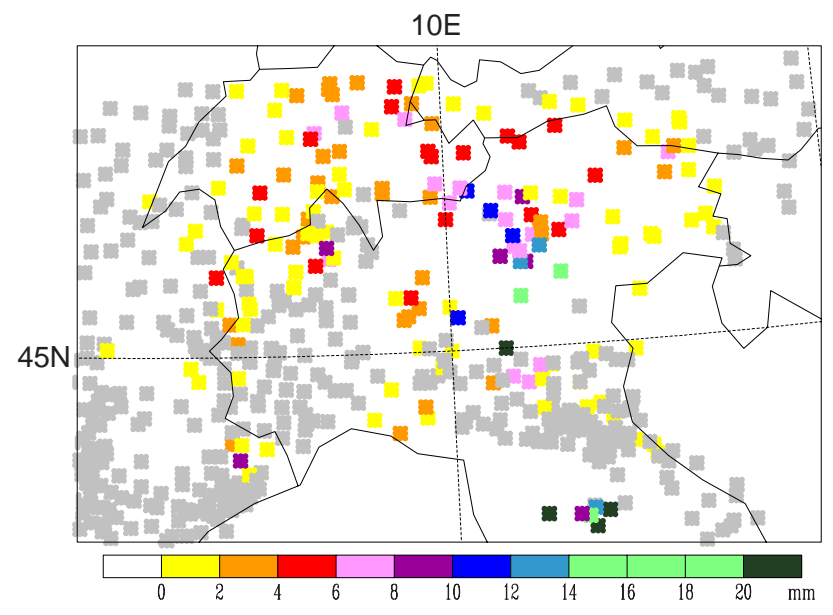

Fig. 2. 1 hour observed accumulated precipitation $(\mathrm{mm})$ from rain gauges ending at 16:00 UTC 20 September 1999.

tering atmosphere as viewed from satellite, taking into account both downwelling and upwelling radiance as well as sea surface reflection with foam effects. It takes into account the gaseous absorption of the atmosphere using a frequencydependent parameterization derived from the comparison of the line-by-line Liebe (1985) model (theoretically valid up $1000 \mathrm{GHz}$ ) with more than 15000 radiosondes. Cloud emission is also empirically parameterized in a non-linear way to liquid water content cloud layer of known height derived from MM5 field. Because the algorithms does not include the scattering processes the raining data are filtered out. Moreover, because the land surface emissivity contaminates the SSM/I measurements, only data over the sea surface are assimilated. Because 3DVAR uses vertical and horizontal physical balance during the minimization procedure, the correction will be found over land too.

The thinning (Järvinen and Undén, 1997) procedure can be applied to the data to reduce their number, and then, their density. In this way, the error-correlation among the SSM/I Brightness Temperatures is reduced, and then, the observation error covariance matrix $\mathbf{R}$ is diagonal (as it usually is), reducing the 3DVAR minimization time. In this work, the effect of applying the thinning or not to the SSM/I data (Brightness Temperature or PW and surface wind speed) will be tested. The thinning window used is of 1 grid points in each direction.

\section{The case}

The selected case is the IOP2b of the MAP (Mesoscale Alpine Programme, http://www.map.ethz.ch) 1999. At 06:00 UTC 20 September 1999, corresponding to the passage of the SSM/I satellite on the Mediterranean area (Fig. 1), an upper level trough, coming from north-west, was moving eastward, advecting warm and humid air from south. Moderate rainfall was recorded on the north of Italy as showed in Fig. 2. 
Table 1. Initial Conditions (first column) and related experiments (last column).

\begin{tabular}{lcccc}
\hline & \multicolumn{2}{c}{ OBS Ingested } & OBS & \\
ICs & TBs & PW\& wind & thinning & Exp. \\
\hline ICNTR & - & - & - & CNTR \\
IRETRa & no & 2809 & no & RETRa \\
IRETRt & no & 690 & yes & RETRt \\
ITBa & 1920 & no & no & TBa \\
ITBt & 725 & no & yes & TBt \\
ITBt19 & 725 & no & yes & TBt19 \\
ITBt22 & 725 & no & yes & TBt22 \\
ITBt37 & 725 & no & yes & TBt37 \\
ITBt85 & 725 & no & yes & TBt85 \\
\hline
\end{tabular}

\section{Experiment design}

A few experiments have been carried out to evaluate the impact of the SSM/I data on both the Initial Conditions and the related forecasts. The ECMWF analyses are used. These data do not include the special observations produced during the MAP. Moreover, no SSM/I data were assimilated into the ECMWF analyses at that time, i.e. 1999. The PW together with the surface wind speed or the Brightness Temperature have been assimilated.

It will allow to assess the different role played by the different kind of SSM/I data (retrieved or not). The experiment design is showed in Table 1; in the first column there are the acronyms used for the study of the Initial Conditions. ICNTR is the case without any data assimilation: it is the ECMWF analysis interpolated to our model grid (Fig. 1). IRETR and ITB refer to the assimilation of the retrieved quantities (PW and wind surface speed) and the Brightness Temperature, respectively. $a$ and $t$ point out the assimilation of all the OBS, or if the thinning process has been applied by 3DVAR to the ingested data. In Table 1 is also showed the number of observations read in for each case.

Four new sets of Initial Conditions are obtained removing one by one the SSM/I frequencies from the ingested dataset. They are the last 4 lines in Table 1 referred by the number of the missing frequency. These special cases are performed using the thinning of the observations that, as already pointed out, it is the correct way to treat the SSM/I data.

The last column of Table 1 shows the forecast experiments produced using the previously improved Initial Conditions.

The experiments start at 06:00 UTC Septemper 1999 and they end after $24 \mathrm{~h}$.
Table 2. Differences between surface stations and analysis for each case at the observation location for Temperature $\left({ }^{\circ} \mathrm{C}\right)$, and horizontal wind component $\mathrm{U}$ and $\mathrm{V}(\mathrm{m} / \mathrm{s})$.

\begin{tabular}{lccccccc}
\hline & \multicolumn{2}{c}{$\mathrm{T}\left({ }^{\circ} \mathrm{C}\right)$} & \multicolumn{2}{c}{$\mathrm{U}(\mathrm{m} / \mathrm{s})$} & \multicolumn{2}{c}{$\mathrm{V}(\mathrm{m} / \mathrm{s})$} \\
OBS-Case & $\mathrm{M}$ & $\mathrm{RMS}$ & $\mathrm{M}$ & $\mathrm{RMS}$ & $\mathrm{M}$ & $\mathrm{RMS}$ \\
\hline ICNTR & -0.09 & 3.17 & -0.10 & 3.10 & -0.73 & 3.37 \\
IRETRa & 0.35 & 3.25 & -0.04 & 3.06 & -0.75 & 3.39 \\
IRETRt & 0.74 & 3.31 & -0.05 & 3.06 & -0.75 & 3.39 \\
ITBa & 0.78 & 3.41 & 0.10 & 3.63 & -0.79 & 3.78 \\
ITBt & 0.22 & 3.21 & -0.01 & 3.15 & -0.73 & 3.44 \\
ITBt19 & 0.21 & 3.20 & -0.02 & 3.14 & -0.74 & 3.43 \\
ITBt22 & 0.10 & 3.17 & -0.09 & 3.11 & -0.77 & 3.39 \\
ITBt37 & -0.04 & 3.20 & -0.05 & 3.15 & -0.68 & 3.42 \\
ITBt85 & 0.19 & 3.21 & -0.01 & 3.15 & -0.72 & 3.45 \\
\hline
\end{tabular}

\section{Model setup}

The model used for this case is the non hydrostatic model MM5, version 3 from PSU/NCAR (Grell et al., 1994; Dudhia, 1993). The selected domains are showed in Fig. 1. The high resolution of the innermost domain is $3 \mathrm{~km}$. The ratio of the spatial resolution between each domain and its mother domain is 3 (i.e. the domain 1 has a resolution of $27 \mathrm{~km}$ ). 29 vertical $\sigma$ terrain following levels are used and the Hong and Pan (1996) and Troen and Mahrt (1986) parameterization is used to describe the planetary boundary layer. The Kain and Fritsch (1990) scheme is used to describe the cumulus convection and the Reisner et al. (1998) parameterization for the explicit moisture scheme.

The Initial Conditions are at 06:00 UTC 20 September 1999 and the related model experiments end after $24 \mathrm{~h}$.

\section{Initial Conditions}

The quality of the Initial Conditions has been evaluated using the statistical parameters

$M=\frac{\sum_{i}^{N}\left(O B S_{i}-I C_{i}\right)}{N}$

and

$R M S=\sqrt{\frac{\sum_{i}^{N}\left(O B S_{i}-I C_{i}\right)^{2}}{N} .}$ 


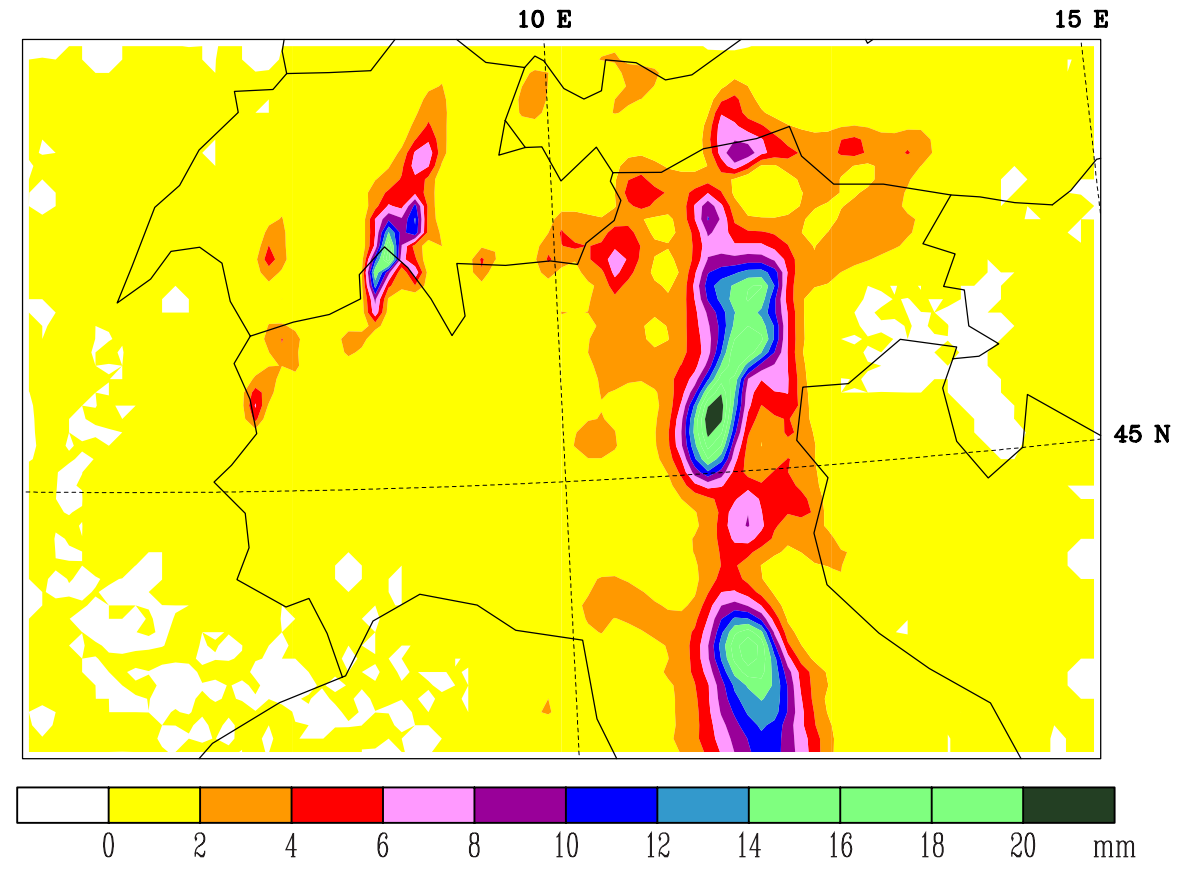

Fig. 3. 1 hour accumulated precipitation (mm) ending at 16:00 UTC 20 September 1999 for CNTR.

where OBS is the observation and IC is the analysis at the $i t h$ station location. The surface stations used for this analysis are the black dots in Fig. 1.

In Table 2 there are the $M$ and $R M S$ for the various Initial Conditions for Temperature and horizontal wind component $\mathrm{U}$ and $\mathrm{V}$. The water vapour mixing ratio is not showed because it presents a mean error larger than $5.19 \mathrm{~g} / \mathrm{kg}$ and a $R M S$ of about $6.0 \mathrm{~g} / \mathrm{kg}$ for all the cases. Because ICNTR has a $M=-5.19$, it means that the assimilation is not able to recover the initial large overestimation, but it increases the error. ICNTR shows a small overestimation of the Temperature respect to the observations $(-0.09)$. The assimilation of the Precipitable Water and surface wind speed (IRETRa and IRETRt) produces a large underestimation respect to ICNTR, especially if the observations are assimilated using the thinning $(M=0.74)$. Same for the assimilation of the Brightness Temperature (ITBa and ITBt), even if the mean errors are lower than the IRETR cases, except for ITBa, meaning that the assimilation of all the Brightness Temperature without thinning largely decreases the quality of the temperature field. The underestimation is partially recovered by the lack of the 22 and $37 \mathrm{GHz}$ frequencies (ITBt22 and ITBt37) on the assimilated dataset, showing the lowest $M$ values of the whole set: 0.10 for ITBt 22 and -0.04 for ITBt37. It has to remind that the RTE algorithm used by 3DVAR exludes the scattering process, therefore the contribution of the $85 \mathrm{GHz}$ channels is reduced. Vice versa for the 22 and $35 \mathrm{GHz}$. It means that their absence on the dataset used for the assimilation, can slightly modify the results; in this case with an improved result.
For the zonal wind, ICNTR shows the larger $M$ value $(-0.10)$, whereas all the data assimilation cases have a lower mean error. The higher value is the one of ITBa $(0.10)$, which also has the unique positive Mean error (underestimation). Remarkable is the results of ITBt $(M=-0.01)$ that shows a zonal field close to the real one. Because the surface wind speed algorithm uses the $19 \mathrm{~V}, 22 \mathrm{~V}$ and both $37 \mathrm{GHz}$ channels, the sensitivity test cases show that removing one of them, the mean error increases, especially for the $22 \mathrm{GHz}$ $(M=-0.09)$ and $37 \mathrm{GHz}(M=-0.05)$ frequencies.

Comparable results are not found for the south-north wind component $(\mathrm{V})$; all cases overestimate the field and all of them, except ITBt37, have a mean error larger than $-0.72 \mathrm{~m} / \mathrm{s}$. Also in this case, ITBa has the largest $M$ value $(-0.79)$, confirming that the assimilation of Brightness Temperature without thinning decreases the quality of the final analysis. ITBt22 shows large mean errors for both the wind components confirming that it is an important channel on the correct estimation of the wind field. As for the water vapor mixing ratio, the results on the $\mathrm{V}$ component confirm that if it exists a large error on the initial field, the data assimilaztion is not able to recover it, but it often increases it.

\section{Forecast Experiments}

In Fig. 3 there is the $1 \mathrm{~h}$ accumulated precipitation for the CNTR experiment. It shows a maximum of precipitation on the Alps between Italy and Switzerland, and an area of high precipitation along the 11E meridian with a maximum on the southern part of more than 20mm (black area in Fig. 3). High precipitation is also found close to the bottom boundary of 

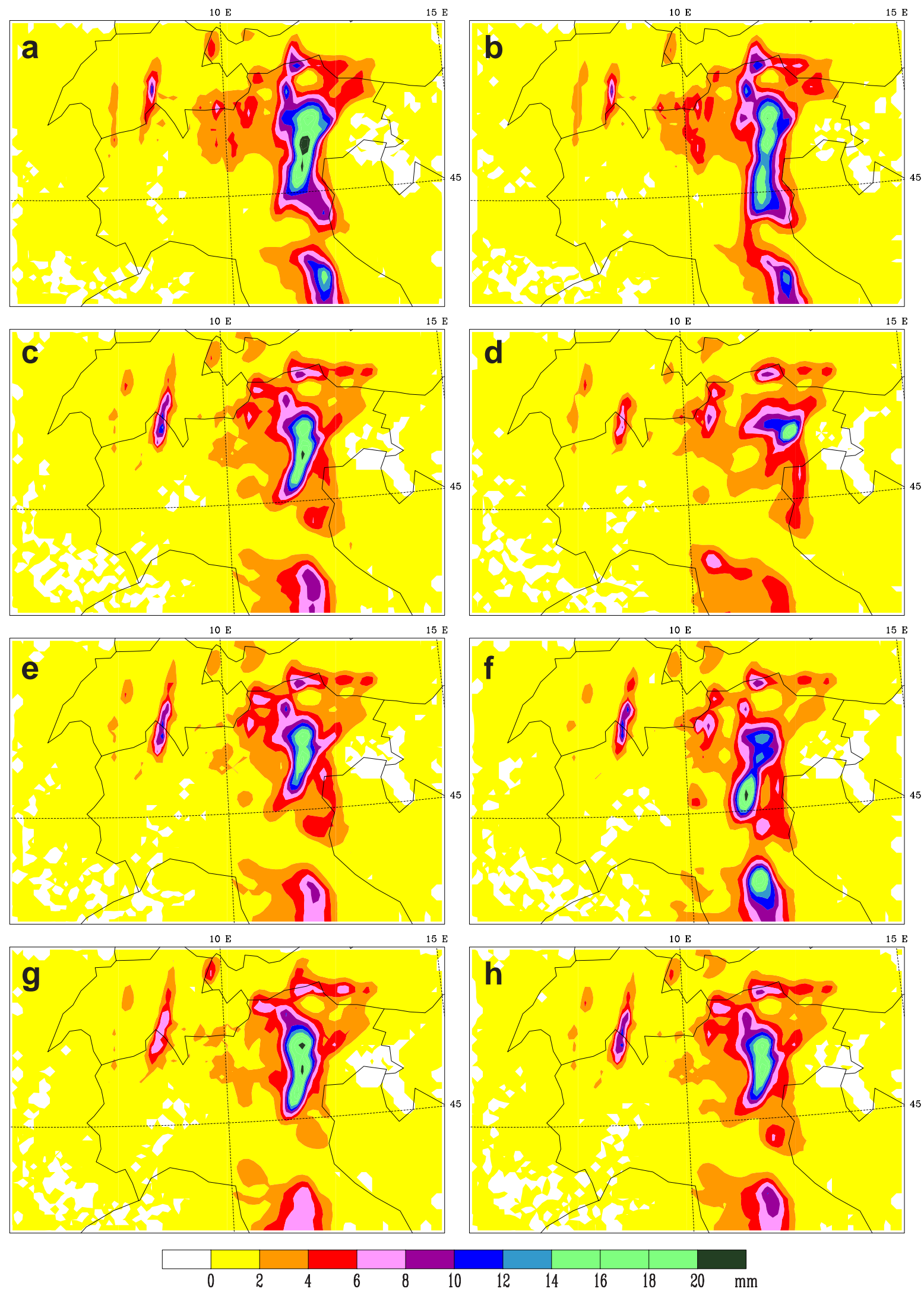

Fig. 4. 1 hour accumulated precipitation ending at 16:00 UTC 20 September 1999 for: (a) RETRt, (b) RETRa, (c) TBt, (d) TBa, (e) TBt19, (f) TBt22, (g) TBt37, and (h) TBt85. 
the domain. The comparison with the observations (Fig. 2) shows a disagreement on the west side of the domain, on the boundary between Italy and Switzerland. RETRt (Fig. 4a) shows a better location of the maximum on the boundary between Italy and Switzerland than CNTR. The area of high precipitation on the south of the domain is reduced, but still incorrectly reproduced. Moreover, the high precipitation area around $11 \mathrm{E}$ and north of $45 \mathrm{~N}$ is enhanced. The assimilation of all the retrieved data produces an improvement of the area on the south of the domain for RETRa (Fig. 4b), but it still overestimate the rainfall along $11 \mathrm{E}$, even if the maxima (black areas in Fig. 4a) disappear. The assimilation of the Brightness Temperature reduces the maximum on the south of the domain especially for the TBa experiment (Fig. 4d), even if this maximum does not exist in the observation dataset. Moreover, this case displaces the reduced maximum westward, on the upslope side of the Apennines, as a result of an orographic precipitation.

The sensitivity experiments show for TBt19 (Fig. 4e) a precipitation distribution similar to the TBt case (Fig. 4a). TBt22 (Fig. 4f) correctly places the maximum of precipitation close to the $45 \mathrm{~N}$ of latitude. However it increases the maximum of precipitation on the south of the domain. This maximum is reduced if the $37 \mathrm{GHz}$ frequency is removed from the dataset ingested by 3DVAR (Fig. $4 \mathrm{~g}$ ). The last cases, TBt85 (Fig. 4h), is similar to TBt19 (Fig. 4e).

\section{Conclusions}

The aim of this paper was to evaluate the impact of the SSM/I data on the precipitation forecast. Both Brightness Temperature or Precipitable Water and surface wind speed have been assimilated by 3DVAR, with and without the thinning procedure, to verify the effect of a different dataset density. Moreover, a set of special test cases to evaluate the impact of each SSM/I frequency of the Initial Conditions have been done. Good results are found for the temperature field if the 22 or $37 \mathrm{GHz}$ channels are removed from the initial dataset. On the other hand, a large improvement on the zonal wind field is found if all the frequencies are assimilated. The assimilation of the retrieved quantities does not produce results as good as for the Brightness Temperature.

The Initial Conditions produced by data assimilation of Brightness Temperature or Precipitable Water and surface wind speed have been used to initialize the MM5 model. The results show that the assimilation of the retrieved quantities places the precipitation too eastward respect to the observation, along a vertical axis parallel to $10 \mathrm{E}$. Moreover, the thinnig (RETRt) produces a large overestimation of the maxima of precipitaion. The assimilation of the Brightness Temperature reduces the area of precipitation in two localised areas, in agreement with the observations, but the location is still too east respecto to the observations, especially for ITBa. Moreover, in this last case the precipitation is largely underestimante on the south of the domain. The comparison among the IRETR cases and the ITB cases shows that the thinning of the observations produces good results if it is applied to the SSM/I Brightness Temperature instead of to the retrieved quantities.

A remarkable result is the dependence of the forecast on the $37 \mathrm{GHz}$ frequency. The quality of the model precipitation decreases if it is removed from the dataset ingested by 3DVAR: the precipitation on the south of the domain is largely reduced and the area of high precipitation on the east sid of the domain is increased in space and amount, not in agreement with the observations. Vice versa for the $22 \mathrm{GHz}$ frequency: it means that the $22 \mathrm{~V} \mathrm{SSM} / \mathrm{I}$ channel, which is sensible to the atmospheric water vapour, introduces an error in the initial conditions that propagates ad increases during the model integrations. Therfore, its removal from the ingested dataset, improves the forecast. It has to be noticed that, although the $85 \mathrm{GHz}$ is located in a window region, then it is also sensitive to atmospheric humidity because of the water vapor continuum term, it is affected by scattering. Thus, because the RTE algorithm is coded for an atmosphere without scattering, it has a small impact on the forecast.

Acknowledgements. A special thanks to all the Italian Regional Centers that help us to collect the data of precipitation for this study: ARPA Piemonte, ERSAF Lombardia, ARPA Emilia Romagna, Osservatorio di Macerata Marche, Ufficio Idropluviometrico e Mareografico di Pisa. Thanks to G. Giuliani for the interpolation routines.

Edited by: L. Ferraris

Reviewed by: A. Mugnai and another referee

\section{References}

Barker, D. M., Huang, W., Guo, Y.-R., Bourgeois, A., and Xiao, Q.: Three-Dimensional Variational Data Assimilation System for MM5: Implementation and initial results, Mon. Wea. Rev., 132, 897-914, 2004.

Courtier, P., Anderson, E., Heckley, W., Pailleux, J., Vasiljeric, D., Hamrud, M., Hollingsworth, A., Rabier, F., and Fisher, M.: The ECMWF implementation of three-dimensional variational assimilation (3D-Var). I: Formulation., Q. J. R. Meteorol. Soc., 124, 1783-1807, 1998.

Dudhia, J.: A nonhydrostatic version of the Penn State-NCAR Mesoscale Model: Validation tests and simulation of an Atlantic cyclone and cold front, Mon. Wea. Rev., 121, 1493-1513, 1993.

Gerard, E. and Eymard, L.: Remote sensing of integrated cloud liquid water: development of algorithms and quality control, Radio Sci., 33, 433-447, 1998.

Gerard, E. and Saunders, R.: Four-dimensional variational assimilation of Special Sensor Microwave/Imager total column water vapour in the ECMWF model., Q. J. R. Meteorol. Soc., 125, 1453-1468, 1999.

Goodberlet, M., Swift, C., and Wilkerson, J.: Remote Sensing of Ocean Surface Winds With the Special Sensor Microwave/Imager, J. Geophys. Res., 94, 14 547-14 555, 1989.

Grell, G., Dudhia, J., and Stauffer, D.: A Description of the FifthGeneration Penn State/NCAR Mesoscale Model (MM5)., NCAR Tech. Note NCAR/Tn-398+STR, 1994.

Gustafsson, N., Berre, L., Hörnqvist, S., Huang, X.-Y., Lindskog, M., B.Navascue, Mogensen, K. S., and Thorsteinsson, S.: Three-dimensional variational data assimilation for a limited area 
model. Part I: General formulation and the background error constraint, Tellus, 53A, 425-446, 2001.

Hollinger, J., Peirce, J., and Poe, G.: SSM/I Instrument Evaluation, IEEE Trans. Geosci. Remote Sens., 28, 781-790, 1990.

Hong, Y. and Pan, H.: Non-local Boundary Layer vertical diffusion in a medium range forecast model, Mon. Wea. Rev., 124, 23222339, 1996.

Hou, A., Zhang, S., and Reale, O.: Variational Continuous Assimilation of TMI and SSM/I Rain Rates: Impact on GEOS-3 Hurricane Analyses and Forecasts., Mon. Wea. Rev., 132, 2094-2109, 2004.

Järvinen, H. and Undén, P.: Observation screening and first guess quality control in the ECMWF 3D-VAR data assimilation system, ECMWF Tech. Memo., Available from the ECMWF, Reading, UK, 236, 1997.

Kain, J. S. and Fritsch, J. M.: A one-dimensional entraining/detraining plume model and its application in convective parameterization, J. Atmos. Sci., 47, 2784-2802, 1990.

Liebe, H.: An updated model for millimeter wave propagation in moist air, Radio Science, 20, 1069-1089, 1985.

Petty, G.: Physical retrieval of over-ocean rain rate from the multichannel microwave imagery. Part I: Theoretical characteristics of normalized polarization and scattering indices, Meteor. Atmos. Phys., 54, 79-99, 1994a.
Petty, G.: Physical retrieval of over-ocean rain rate from the multichannel microwave imagery. Part II: Algorithm implementation, Meteor. Atmos. Phys., 54, 101-121, 1994b.

Petty, G.: An intercomparison of oceanic precipitation frequencies from $10 \mathrm{SSM} / \mathrm{I}$ rain rate algorithms and shipboard presentweather reports, J. Geophys. Res., 102, 1757-1777, 1997.

Petty, G. and Katsaros, K.: The response of the Special Sensor Microwave/Imager to the marine environment. Part I: An analytic model for the atmospheric component of observed brightness temperatures, J. Atmos. Ocean. Tech., 9, 746-761, 1992.

Petty, G. and Katsaros, K.: The response of the Special Sensor Microwave/Imager to the marine environment. Part II: A parameterization of the effect of the sea surface slope distribution on emission and reflection, J. Atmos. Ocean. Tech., 11, 617-628, 1994.

Reisner, J., Rasmussen, R., and Bruintjes, R.: Explicit forecasting of supercooled liquid water in winter storms using the MM5 mesoscale model, Q. J. R. Meteorol. Soc., 124B, 1071-1107, 1998.

Troen, I. and Mahrt, L.: A simple model of the atmospheric boundary layer: Sensitivity to surface evaporation., Bound.-Layer Meteor., 37, 129-148, 1986.

Tsuyuki, T.: Variational Data Assimilation in the Tropics Using Precipitation Data. Part III: Assimilation of SSM/I Precipitation Rates., Mon. Wea. Rev., 125, 1447-1464, 1997. 